\title{
Entrevista a Mónica Cragnolini
}

Vir Cano

IIEGE

Mónica B. Cragnolini es profesora regular de "Metafísica" y "Problemas especiales de Metafísica" en la FFyL de la UBA donde ha creado y dicta también la materia "Filosofía de la animalidad". Es directora de la Maestría en Estudios Interdisciplinarios de la Subjetividad por la misma universidad e Investigadora Principal del Consejo Nacional de Investigaciones Científicas y Técnicas (Conicet). Es autora, entre otros libros, de: Nietzsche: camino y demora; Moradas nietzscheanas. Del símismo, del otro $y$ del entre; Derrida, un pensador del resto; Extraños animales: filosofia y animalidad en el pensar contemporáneo, ¿a quién le importan los animales? Los estudios de la animalidady las humanidades. Es, además, compiladora, entre otros, de Comunidades (de los) vivientes; "Quién"o "qué". Los tránsitos del pensaractual hacia la comunidad de los vivientes; Extraños modos de vida. Presencia nietzscheana en el 


\section{debate en torno a la biopolítica; Extrañas comunidades. La} impronta nietzscheana en el debate contemporáneo; Poramor a Derrida; Modos de lo extraño. Subjetividady alteridad en el pensamiento postnietzscheano; Entre Nietzschey Derrida. Vida, muerte, sobrevida. Ha compilado asimismo con R. Maliandi La razón y el minotauro, y con G. Kaminsky, Nietzsche actual e inactual, Vols. I y II. Es directora de la revista Instantesy Azares-Escrituras nietzscheanas (ex Perspectivas Nietzscheanas, 1992-2000).

V.C.: Antes que nada quiero decir que es un privilegio para mí poder entrevistarte Mónica, porque sos la persona que me formó y que me ayudó a pensar otra manera del quehacer filosófico y otro modo de habitar la institución académica, además de ser una inspiración para tantas personas a las que has conmovido con tus escritos, tus clases y tus charlas. En ese sentido, quisiera preguntarte cómo pensás tu (im)propia trayectoria intelectual, esa que se inició con reflexiones en torno a la ética y la razón imaginativa, que pasó por autores como Nietzsche y Derrida que fueron malditos para la academia local, por mencionar solo algunxs, y que en la actualidad se adentran en el incipiente campo de la filosofía de la animalidad. ¿Cuáles son las torsiones, las continuidades y las rupturas que atraviesan este amplio derrotero filosófico? ¿Y cómo fue -y es- este viaje intelectual en la academia local?

M.B.C.: Yo lo que diría en primer lugar es que, en realidad, si tengo que pensar cómo empezó mi trayectoria intelectual, comenzó por el tema de la filosofía de la religión. Cuando yo entré en la carrera de Filosofía, lo que me interesaba era la filosofía de la religión y, sobre todo, la mística. Me interesaban particularmente esos procesos que, a diferencia de la religión (que implica siempre un religare con lo divino, con la totalidad), tienen que ver con la cuestión de la ruptura de los vínculos con la totalidad. De hecho, cuando cursaba Sánscrito y Filosofía de la India con el profesor Fernando Tola, me invitó a trabajar ese tema con él en el CIF (Centro de Investigaciones Filosóficas) y comencé a leer muchos textos sobre mística en las religiones orientales.

Ahora bien, ese tema que me interesaba tanto me hizo ver que para estudiar esa cuestión en las religiones orientales era necesario estudiar muchas lenguas diferentes a las que, por el tipo de enseñanza que había en la facultad, no se tenía acceso, o muy poco. Teníamos un año de sánscrito nada más, y un año de árabe. Entonces, cuando llegó el momento de hacer mi tesis de licenciatura, decidí hacerla sobre Nietzsche porque era un autor sobre el cual había cursado varios seminarios con el profesor Bruno Piccione, quien también fue mi director de tesis. Había cursado esos seminarios, sobre todo, como una rebelión contra su pensamiento, por la línea que venía trabajando en torno a la filosofía de la religión. Luego, cuando comencé también a vincularme con Ricardo Maliandi en el Centro de Investigaciones Éticas y se abrió la convocatoria a becas de doctorado (porque era el momento en que surgía esa figura del becario en el Conicet), él me instó a presentarme. Ocurre que en ese momento postularse con Nietzsche no era aceptado porque había una dirección muy específica de ingreso dentro del Conicet en el ámbito de la filosofía que tenía que ver más con la filosofía analítica. Entonces, Maliandi me convenció de presentarme con un tema de la ética. Así fue como estuve muchos años trabajando como becaria la problemática de la fundamentación de la ética, sobre todo en la escuela de Frankfurt y en la ética de la comunicación (Habermas, Apel). Pero, al mismo tiempo, iba haciendo mi doble vida: la escritura de mi tesis de doctorado sobre Nietzsche. Eso fue muy llamativo, porque habiendo tenido una beca para investigar otros temas, en donde no estaba incluido Nietzsche, mi tesis de doctorado fue sobre su filosofía, sobre la cuestión del pensamiento y la ética, para ser más precisa. Por eso tuve dos directores, uno que fue Adolfo Carpio, más vinculado con la parte metafísica, y el otro fue Ricardo Maliandi, más vinculado con la parte ética. Entonces, mi tesis de doctorado fue sobre el pensamiento y la acción en el posnihilismo, totalmente basada en Nietzsche.

Ahora bien, vos me preguntabas cómo sigue eso después, cómo viene la ética. Bueno, desde ahí viene la problemática de la ética. La "razón imaginativa" es un concepto que empecé a desarrollar para 
pensar el pensamiento de Nietzsche más allá de su interpretación como irracionalista. Eso era muy gracioso, y era una de las peleas constantes que tenía con mi director, Ricardo Maliandi, porque él decía que Nietzsche era un irracionalista y yo le señalaba que ningún autor podía ser irracionalista, porque sino no escribiría nada. Nunca podíamos llegar a un acuerdo; él era un defensor de la ética de la comunicación, y obviamente se colocaba en ese ámbito de una razón pensada más dentro de las líneas de la razón moderna. Entonces, te decía, por esos años me venía dedicando a Nietzsche. Empecé a organizar jornadas, y surgió en 1992, en un seminario sobre Nietzsche que dicté en la facultad, un grupo de estudiantes que me planteó armar una revista que fue Perspectivas Nietzscheanas, y que después en 2000 se convirtió en Instantes y AzaresEscrituras Nietzscheanas. A medida que iba trabajando estos temas, me daba cuenta de que lo más importante de Nietzsche, desde mi punto de vista, se encontraba en lo que dice en la actualidad. Es decir, más allá de hacer el trabajo del docto, que de hecho uno lo hace, hay que pensar qué es lo que dice el autor para el presente. Porque uno hace con los autores con los que trabaja lo que Nietzsche llama "el trabajo del docto", que es ir recopilando elementos, ver las fuentes, etc.; pero creo que claramente, al menos esa es mi posición filosófica, no hay que quedarse solo con eso. En tal sentido, empecé a plantearme la pregunta de cómo Nietzsche está presente y cómo resuena en los autores posnietzscheanos, sobre todo en los autores de línea francesa, aunque no solamente.

El pensamiento de Nietzsche, desde mi punto de vista, está presente en muchas líneas del pensamiento actual y creo que lo seguirá estando por mucho tiempo, si uno se atiene a aquello que él mismo dijo sobre que no iba a ser entendido hasta después de dos siglos. Así, empecé a plantearme la presencia de Nietzsche en el contexto contemporáneo, y sobre todo me preocupaba qué podía aportar Nietzsche al pensamiento de la alteridad. Esto, como te señalaba, atendiendo a que a mi alrededor se lo vinculaba rápidamente con posiciones individualistas, que fue una línea de interpretación muy del siglo XIX o principios del siglo XX, y a la que yo no le veía mucho sentido estando ya en la segunda mitad del siglo XX. Entonces, empecé a trabajar la presencia de Nietzsche en los debates contemporáneos en torno a la alteridad, a la biopolítica y a la cuestión de la animalidad. Me parecía que un autor tan deconstructor de la subjetividad como es Nietzsche, que se ríe tanto del yo y que tiene ese término tan fuerte pero tan claro para explicar este pensamiento que es el de la “ipsisimosidad", podía aportar, desde la crítica de la subjetividad, cuestiones valiosas para el pensamiento contemporáneo de la alteridad. El otro no es solo el otro humano, sino que es el otro viviente, en términos actuales diríamos la tierra toda. Entonces, a partir de ahí se configura toda la problemática que parte de la biopolítica y de la animalidad.

V.C.: ¿Y cómo fue la recepción institucional? Me interesaba que nos contaras algo en relación a trabajar autores que, como comentaste sobre tus tesis de licenciatura y doctorado, fueron extrañamente recibidos. Nietzsche cobró mucha legitimidad por lo que vos hiciste todos estos años, pero cuando iniciaste era otra historia. Me pregunto si con Filosofía de la animalidad pasa algo parecido, en cuanto a introducir campos novedosos para la academia local. ¿Cómo es ingresar temáticas, discusiones, autores y textos que no están canonizados?

M.B.C.: Hay que contar un poco de la historia de la carrera de filosofía para entender eso. Cuando yo fui estudiante (cursé durante toda la dictadura cívicomilitar) se daba Nietzsche, se daba Marx, se daban muchos autores que, cuando se cambia el plan de estudios con el comienzo de la democracia y con una línea de pensamiento dirigiendo la carrera que tenía que ver con la filosofía analítica, desaparecen. Se suprime todo lo que se consideraba "medio raro", como Nietzsche, pero también la Filosofía Oriental que desapareció totalmente, Filosofía de Oriente y de Occidente, Sánscrito y Filosofía de la religión. Desaparecen todas esas materias que quienes asumieron en ese momento la dirección de la carrera consideraban que no iban dentro del canon. Hubo un período, entonces, en el que se consideró que Nietzsche era un autor que no tenía relevancia para el pensamiento filosófico; y no solo eso, sino que era peligroso también. A mí me ha pasado, en un concurso de JTP de Metafísica, que me plantearan: "¿usted se dedica a Nietzsche? ¿No es un autor peligroso?". Surgían este tipo de asociaciones que en alguien que no se dedica a la filosofía una las entiende, pero en alguien que se dedica a la filosofía son muy llamativas. Ese fue el problema de insertarlo luego de la democracia, luego de haber atravesado el proceso de formación.

Cuando comencé a dedicarme a la cuestión de la animalidad, muchos colegas me decían "¿Ahora te dedicás a los animalitos? ¿Vas a poner un PetShop?”. Aparecía nuevamente esa idea de que es un tema menor dedicarse a la problemática de la animalidad; de la misma manera que ese jurado del concurso de JTP consideraba que Nietzsche era un tema peligroso. Que alguien hoy, en el siglo XXI, considere que la filosofía no se puede dedicar al tema de la animalidad también es muy llamativo. Yo creo que tiene que ver con el hecho de que las humanidades están en crisis hace un montón de tiempo y que es nuestra tarea 
contribuir a su deconstrucción y a demostrar que una facultad de humanidades no puede ser una facultad en la cual se siga pensando al existente humano como lo más importante de toda la creación, de toda la tierra. Y, bueno, también el existente humano masculino, porque es cierto que ahora, desde hace un tiempo, el feminismo ha logrado entrar con mucha fuerza, pero hasta no hace mucho tiempo la situación era muy diferente. Eso se ve muy bien en lo que el feminismo llama el techo de cristal. Si uno hace un análisis del cuerpo docente de la carrera de filosofía se va a dar cuenta de que las mujeres que alcanzan el cargo más alto de titular son muy pocas o lo alcanzan cuando son muy grandes. Mis colegas varones, los que he tenido desde que ingresé en el claustro docente como adjunta en 2000, llegaron a los cargos siendo mucho más jóvenes que nosotras. Hoy se acepta el feminismo, pero hay que ver si se lo acepta solo como discurso, porque hay que esperar que tiempo deconstruya también las estructuras institucionales en donde está colocado el existente humano masculino.

V.C.: Tus desarrollos actuales se centran en cuestiones ligadas a pensar la animalidad, la desjerarquización de formas de vida no-humanas y la producción neoliberal de un modelo de mercado basado en la injusticia y el sacrificio, desde la perspectiva de un $\triangle$ mundo superhumanizado囚, como afirmás en el texto compilado en el volumen colectivo La fiebre. Según tu opinión, ¿en qué sentido la pandemia de COVID-19 reforzó o, por el contrario, contribuyó a socavar esta organización del mundo y estas jerarquías de lo viviente? En la escena de emergencia sanitaria, social, política, económica y afectiva actual, ¿es posible evitar caer en el más pesimista de los nihilismos, para decirlo con Nietzsche, o en la "fe cómica区 frente a las soluciones definitivas, como advierte Donna Haraway? ¿Qué otras maneras y tesituras afectivo-intelectuales podemos desplegar y explorar en estos momentos?

M.B.C.: Yo lo vincularía con lo que acabo de decir respecto de la crítica a una facultad de Humanidades, porque creo que la pandemia, por lo menos para mí, hizo evidente que el modo de ser humano no va más, que la manera en la cual nos hemos instaurado sobre el planeta todo es un modo que tiene que ser puesto en cuestión, criticado, deconstruido. Como yo me dedico a la problemática animal, me interesó el origen de este virus en relación con la zoonosis. La verdad es que estuve leyendo muchísimo material sobre el tema y me impactó de qué manera esto, que supuestamente a nosotros nos llamaba la atención, ya estaba anunciado por muchos virólogos desde hace mucho tiempo. Ese anuncio que hacían desde hace mucho: "habrá grandes pandemias", muchos lo vinculaban con el virus de la influenza y con otros virus; pero el punto es que todos esos virus tienen vinculación con la cuestión animal, más precisamente, con el modo en que tratamos a los animales. En el caso de este virus, suponiendo que el origen sea zoonótico (es decir, que se trata de un virus que afecta a animales no-humanos y que "saltó" a un humano) hay todo un cuadro de situación del modo del ser humano que somos que se hace evidente.

Lo que se hace evidente es que para construir barrios privados o para deforestar, expulsamos a las aves y a los animales de su ámbito propio, y esos animales estresados buscan otro hábitat y se van a las grandes urbes o a lugares cercanos a las grandes urbes. Así, animales estresados contaminan a otros animales estresados, que son los animales de producción intensiva que se encuentran hacinados y están alimentados con elementos que le interesan al existente humano para que la carne sea mejor, a la vez que están todo el tiempo inyectados con antibióticos porque se sabe que el sistema inmunológico se deprime en esas condiciones. Entonces, se sabe que ese virus "salta" a una especie animal de producción intensiva y luego al humano. En ese sentido, yo creo que la zoonosis revela el modo de ser que somos, porque podemos apropiarnos de cualquier parte del planeta para construir nuestros barrios, para deforestar, ¿y para qué deforestamos?, para cultivar alimentos para animales de producción intensiva que viven en las condiciones que señalaba y a quienes les exterminamos sus vidas, sus existencias. Eso generó esta zoonosis, pero hay muchas otras. Ya pasamos por la gripe porcina, la gripe aviar, y luego China anunció que desde hace tiempo tiene la gripe porcina africana, y ahora también apareció otro virus que aún no sabemos de dónde viene...

Yo creo que en la pandemia hizo eclosión que el ser humano, así como lo pensamos, no va más. Ahora el tema es qué va a acontecer con esto, si realmente los intereses económicos de las grandes empresas van a permitir que esto sea algo más que un intervalo, un paréntesis, una epojé por el cual pasamos para luego volver a la normalidad (que es volver a explotar el planeta), o si algo se va a transformar. En fin, se hizo evidente el biocapitalismo, es decir, el modo en que el capitalismo hoy en día considera la vida como mercancía. No solo la vida de los existentes animales sino también la de los existentes humanos. Pensemos en el mar Mediterráneo como la gran fosa común de montones de migrantes y la situación agravada de esos migrantes en esta situación de pandemia. Esos migrantes también viven hacinados.

La pregunta, entonces, es si vamos a poder transformar algo, cambiar algo o si vamos a ir a formas diferentes de capitalismo, como por ejemplo todo lo que se llama el "capitalismo verde", es decir, sustituir energías 
fósiles como combustible por biomasa, etc. Hay una gran tendencia hacia el capitalismo verde, que supone seguir usando el planeta todo como recurso utilizable y eso es lo que yo creo que tenemos que cuestionar. La pandemia es un buen tiempo para problematizar eso. Sinceramente, no tengo ninguna esperanza en el existente humano tal como es. Tal vez sea el momento de una transformación.

V.C.: ¿Te inclinás más hacia al pesimismo nietzscheano?

M.B.C.: Sí, me inclino al pesimismo, esa enfermedad de la piel de la tierra.

V.C.: Recuperando la cuestión de las jerarquías ontológicas y los modos de producción de injusticia y violencia social y vital, quisiera preguntarte por la relación —-según tu entender- entre los movimientos antiespecistas y las políticas feministas y sociosexuales en general. Muchas activistas veganxs afirman que $\nabla$ sin antiespecismo no hay feminismo囚. A ello podríamos sumar la siguiente inquietud: ¿es posible el antiespecismo sin el feminismo? $Y$ me permito aquí el doble nominalismo, dado que sabemos que los movimientos sociales y emancipatorios son siempre plurales y complejos.

M.B.C.: Yo creo que el sexismo, el racismo y el especismo siempre estuvieron juntos. Los críticos del sexismo también son críticos del racismo y del especismo. Lo que pasa es que, desde el punto de vista de los movimientos, el poner el acento en un aspecto no siempre ha tenido en cuenta la necesaria solidaridad de esos elementos en el siglo XXI. ¿Por qué digo esto? Si nos ponemos a pensar en el feminismo, con la cantidad de siglos que tiene en obra, es interesante recordar que si bien ha habido movimientos feministas claramente en el siglo XIX, ya en el siglo XVIII Mary Wollstonecraft escribía Vindicación de los derechos de la mujer y un profesor se burló de ella y publicó Vindicación de los derechos del animal. Al burlarse de esta manera, hizo evidente que los derechos de la mujer y los derechos del animal deberían estar juntos. Eso pasó, si no me equivoco, en 1792. Pasamos el siglo XIX con los movimientos feministas de entonces, pasamos el siglo XX con los movimientos feministas de ese siglo, y pareciera que continuamente fuera necesario empezar de nuevo. Entonces yo, por una cuestión práctica y de economía, lo que pienso es que los movimientos feministas, los movimientos antirracistas y los movimientos antiespecistas tienen que unirse porque no queda más tiempo.

Si bien es cierto que las mujeres votamos, que vamos a la universidad, desde el punto de vista de las costumbres, yo no veo mucho cambio, mucha transformación. Esa es mi opinión pesimista. Entonces, en ese sentido, creo que es necesario que esas tres formas de críticas del sexismo, del racismo y del antiespecismo estén vinculadas, porque tienen que ver con la violencia estructural contra animales, extranjeros, niños y mujeres que siempre implica que hay un modo de ser del existente humano (que es el masculino, el macho, el soberano) que tiene derecho sobre todo lo demás. Y habría que decir que este lugar también puede ser ocupado por una mujer, porque una mujer puede ser un ipse soberano que se quiere imponer sobre los demás. Creo que ahí lo que está presente es la cuestión del poder, de cómo se piensa el poder: si se lo piensa jerárquicamente, es decir, en términos del orden piramidal donde quien está en la punta de la escala ejerce el poder sobre Ixs otrxs, o se lo piensa circulando de otra manera. Si se lo piensa jerárquicamente, obviamente siempre va a existir aquel que domine. En ese sentido, yo siempre menciono esa expresión de Horkheimer en Crepúsculo que dice "todos somos amables con aquel que es poderoso, pero con aquel que es débil, todos somos tratantes y carniceros". Este pasaje me parece muy bueno porque muestra muy bien de qué manera está vinculado el trato de las personas y el trato de los animales y hace evidente esta idea del ipse soberano que tiene la atribución y el poder de disponer del otrx. Me parece que lo que está presente en esa idea de poder se podría resumir así: "yo puedo disponer del otro, el otro es mi propiedad, el otro está bajo mi dominio". En ese sentido, creo que ver la vinculación entre estas tres cuestiones me parece muy importante, $y$ sobre todo digo esto porque me pongo a pensar en los siglos XVIII, XIX, XX y iXXI! y recién estamos en esta etapa del feminismo, y me pregunto: ¿qué va a pasar con la cuestión animalista? ¡Vamos a estar en el siglo XXV planteando todavía el tema! Entonces, me parece que por una cuestión práctica, teórica y de violencia estructural estas tres luchas deben unirse. Ahora, es cierto que dentro del feminismo, si bien hay corrientes que aceptan esto, hay otras a las que no les parece relevante.

V.C.: Hay una inquietud que encuentro en tus textos y que es común a muchas de las preocupaciones más acuciantes en los movimientos sociosexuales contemporáneos, así como en otros campos de la lucha popular: la recuperación constante y la proliferación del lenguaje de la guerra para pensar nuestros activismos. ¿Podrías explayarte sobre los límites y los problemas que dicha aproximación supone para la disputa y la transformación de los sentidos de lo humano, de la vida, de la lucha?

M.B.C.: Yo creo que el lenguaje de la ontología de guerra es un lenguaje masculino, es decir, es un lenguaje que históricamente está determinado por la 
forma en que el existente humano masculino se ha enseñoreado sobre todo el planeta. Vos mencionabas ese texto de La Fiebre y a mí me molestó mucho cuando se inició la pandemia que la lucha contra el COVID se pensara en términos de una guerra contra el virus, incluso había una propaganda en la cual se decía "el maldito virus", lo que supone una moralización del virus que se relaciona con esta idea de una ontología de guerra. Ello supone pensar a todo lo que es diferente, a todo lo que no entra dentro de la categoría de normalidad, a todo lo que no es del orden de lo canónico, como un enemigo contra el cual hay que luchar. Entonces, ¿qué pasa ahí? Me parece que cuando unx plantea demasiado las cuestiones en términos de guerra, lo que se hace patente es el vivir contra y no el vivir con. En ese sentido creo que hemos vivido contra mucho tiempo. Hemos vivido contra lo viviente; el existente masculino ha vivido contra las mujeres, contra los niños y contra los animales. Creo que sería bueno ponernos a pensar en términos de vivir con, y no vivir contra, ni tampoco vivir de, es decir, vivir del otrx.

Entiendo que en las luchas hay que ver cuál es el oponente, el adversario y ver de qué manera luchar contra los sistemas de pensamiento y de prácticas que ese adversario impone; pero creo que si uno se queda demasiado en el lenguaje de la guerra, genera mucho resentimiento. Así, se plantea la relación con el otrx en términos de resentimiento y de aniquilación, porque el otrx es ese enemigo que debe ser aniquilado, porque es el diferente, el que me impone límites, el obstáculo para mi desarrollo, etc. En ese sentido, me parece que lo que habría que pensar es el vínculo que tiene el poder con la apropiación y con la disponibilidad del otrx y plantearse, - lo que ya han planteado Agamben y otros autores contemporáneos-que es la cuestión del impoder. ¿Cómo podríamos pensar, desde una deconstrucción del yo que siempre ha sido el yo poderosx, el ipse sujetx, soberanx, etc., un impoder (y me parece que Nietzsche está dentro de esta línea de pensamiento a pesar de que se plantea el ultrahombre como superhombre que va a dominar toda la tierra)?

Yo creo que lo que habría que plantear es la cuestión de un impoder en términos de respeto a la vulnerabilidad que es el otrx y que es unx. La perspectiva del impoder, me parece, permitiría pensar muchas cuestiones más allá de las luchas en términos de una ontología de guerra. Ahora bien, es cierto que cuando una señala esto le dicen: "bueno, ¿y qué hacemos entonces?”. Es la pregunta por cómo pensar la cuestión práctica en términos del impoder. $Y$ aquí yo insistiría en el hecho de vivir con, en lugar de poner el acento en el vivir contra. Porque si una plantea toda lucha política en términos del enemigx que tiene que ser exterminadx, obviamente no se puede plantear ninguna idea de comunidad posible, porque no se puede convivir con nadie si no es igual a unx mismx. Me parece que hay escondido, en el seno de la cuestión de la militancia, entendida como lucha contra el enemigx, la cuestión de la mismidad, está escondido un: "bueno, terminaremos siendo los mismos". Precisamente, si unx es un defensor de un pensamiento de la diferencia, creo que habría que hacer el ejercicio intelectual y práctico de ser hospitalarix con el otrx que piensa diferente pero que no por eso tiene que ser aniquiladx; de lo contrario, estamos siempre en una guerra sacrificial: si no es contra los animales, será contra Ixs machistas, o será contra otras formas que uno considera no adecuadas para vivir en este momento en el mundo. Esta posición termina considerando como adecuada solo la propia forma y acaba afirmando una mismidad que es justamente contra lo cual se estaba luchando.

V.C.: Quisiera preguntarte por tu mirada respecto de la relación entre la academia y los movimientos sociales. En este sentido, ¿cómo pensar ese complejo, imbricado y polémico vínculo entre las luchas sociales, la investigación y la docencia? ¿Cómo habitás la relación entre tu activismo en defensa de los animales no humanos y tu vida académico-institucional?

M.B.C.: Yo creo que hay un problema que siempre se hace patente en el lugar del intelectual que es la creencia de que, porque unx se dedica al pensamiento, sabe cuál es el bien del otrx. Eso lo planteó muy bien Platón en La República, señalando de qué manera solamente aquel que llega al lugar más alto, al mundo de las ideas, podrá gobernar a Ixs otrxs. Entonces, en ese sentido y desde mi punto de vista, yo descreo de esa figura del intelectual que sabe cuál es el bien del otrx, que le dice al otrx lo que tiene que hacer, qué caminos transitar, etc. Vos me preguntás cómo pensar la cuestión de la academia, donde algunxs podrían pensar que estamos Ixs que pensamos las cuestiones que Ixs otrxs pondrían luego en práctica, y a mí me parece que ahí hay un problema de base que es el hecho de pensar que quien vive en la academia puede darle elementos al otrx que se dedica a la lucha en términos políticos concretos para que su lucha esté mejor direccionada. Yo no creo en eso, no creo que como personas dedicadas al pensamiento tengamos ningún tipo de función en ese sentido, ni que seamos funcionarixs de la humanidad, ni que podamos decirle a los demás qué caminos deben transitar. Sí creo que quienes nos dedicamos a la vida académica, con nuestros escritos, tratamos de decir algo, tratamos de pensar cuestiones que les pueden ser útiles o no a quienes se pronuncien en la cuestión animalista. 
A lo mejor alguien que se dedica a las cuestiones animalistas lee lo que yo escribo y le puede ser útil para pensar algo, pero no necesariamente debe ser así, y seguramente no es así.

Entonces, yo creo que quienes nos dedicamos a la vida académica asumimos la escritura como una forma de militancia, es decir, que unx está diciendo qué es lo que piensa, cómo se ubica en el mundo. Yo pienso que la escritura, de hecho, es una forma de praxis. O sea, la escritura no es una forma de pensamiento aislada o algo que acontece, sino que es una praxis en sí misma. Mi práctica, como yo no participo en ninguna organización animalista, es la escritura y no tengo ninguna intención de decirle a alguien qué tiene que pensar, ni por dónde debe transitar.

V.C.: Por último, y más que para cerrar para seguir abriendo, quisiera recuperar tu insistente invitación a pensar a la filosofía desde el temblor. ¿Podrías contarnos por qué, para vos, el filosofar y el pensar se vinculan al temblor, la incertidumbre y el riesgo? Y en esta línea, ¿podemos imaginar y practicar la docencia desde la experiencia de la conmoción y el $₫$ peligroso quizás $\bigotimes$ ?

M.B.C.: Hace unos años me habían pedido de la revista Nombres de Córdoba que escribiera cuál era mi idea de la filosofía y yo le puse de título (y fue lo que desarrollé en ese artículo) tres verbos en infinitivo: caminar, demorarse, temblar. Justamente, me parece que ahí, al menos en el tránsito que yo he hecho desde el punto de vista del pensamiento, se encuentra lo que yo considero que es la filosofía. Es ahí que viene la exposición y el riesgo, que es lo que vos señalabas. ¿Por qué verbos en infinitivo? Porque se trata de acciones, de tránsitos, y no de seguridades; y esto se liga a la cuestión de la docencia.

Yo creo que, tal vez, cuando se es muy joven y uno recién se recibe y va a dictar clases tiene la idea de que lo que debe hacer patente frente a los estudiantes es la seguridad que posee con respecto a lo que sabe, lo que ha estudiado, etc. Por suerte, esa seguridad dura muy poco tiempo. Justamente, el ejercicio de la docencia nos coloca en una situación de bastante incertidumbre, en una posición de cuestionamientos, y yo creo que esto es lo mejor que te puede suceder. Yo transité la docencia en la escuela primaria, en la escuela secundaria y en la Universidad; y en todos los niveles para mí la docencia es maravillosa por el hecho de que el otrx te asombra, te deja sin palabras, te deja en suspenso. La docencia es maravillosa porque hace patente esa condición que tenemos de expuestos ante el otrx. Por eso, frente al desconcierto, más que intentar rápidamente cerrar la cuestión del otrx buscando alguna respuesta rápida, que termina siendo una respuesta que no está pensada y que es un indicio de que unx quiere parecer seguro frente al otrx, yo creo que lo mejor que podemos hacer frente a lxs estudiantes es permanecer expuestos a la incertidumbre, a la transformación, al cambio que significa la docencia como encuentro con el otrx. De lo contrario, sustituiríamos la docencia por la información, por "bajar" contenidos y no tendríamos ese vínculo que tenemos con lxs estudiantes en las clases.

Pasamos un año donde no tuvimos clases presenciales pero las clases sincrónicas (online) también pueden ser una posibilidad de ese encuentro, aunque con otras características, obviamente. También hay que exponerse a esas transformaciones que implican las condiciones en las que estamos viviendo. Seguramente viviremos un año más, o incluso dos en esta situación, de modo que, en lugar de hacer grandes críticas contra las plataformas virtuales, tal vez sea mejor estar expuestos a la incertidumbre que implica aceptar que estas son las condiciones en las cuales se ejerce la docencia ahora, y ver de qué manera podemos generar ese elemento vinculante que se da en un encuentro con estudiantes en donde, vuelvo a decir, lo más importante no es bajar contenidos. Es por eso que no me agrada mucho cuando, en estos tiempos de pandemia, se sustituye la clase sincrónica por videos armados, donde hay un docente que está hablando solo y entonces el estudiante escucha y no tiene ningún vínculo.

Como decía, para mí la docencia es una exposición a la incertidumbre que implica el encuentro con otrx y que, como cualquier encuentro con otrxs, siempre es del orden de la sorpresa. Uno no sabe qué puede acontecer, no puede dominar el sentido de lo que va a pasar y, por eso mismo, la clase es tan transformadora para nosotrxs y para Ixs estudiantes. En ese sentido, así como Juan L. Ortiz decía que "la poesía es la intemperie sin fin" que "está cruzada por llamada sin fin", yo creo que la docencia también es algo del orden de la intemperie: estamos expuestos frente a Ixs otrxs, estamos sin armadura frente a lxs otrxs. Creo que lo peor que se puede hacer es exponerse a Ixs otrxs con las armaduras de un supuesto saber que, claramente, ya cuando unx se recibe en filosofía, se da cuenta que lo que aprendió no es nada, que hay un montón de cosas más para seguir estudiando, para seguir investigando, para seguir trabajando, etc. Por eso me gusta mucho esa expresión de Juan L. Ortiz y la usaría para pensar la docencia. La docencia es la intemperie sin fin, cruzada, crucificada, por llamadas. Creo que, en ese sentido, se hace patente la problemática de la incertidumbre, de la no seguridad y de eso que yo vinculo con temblar ante el otrx. En el texto que te mencioné, hablaba de la filosofía como caminar, porque dedicarse al pensamiento es estar caminando constantemente en el sin sentido, atravesando el sin sentido, temblando, en el sentido 
de que siempre temblamos ante el otrx, porque el otrx es el del orden del acontecimiento, y por tanto no puede ser previsto, no puede ser programado. Si fuera previsto o programado, estaríamos apropiándonos del otrx. En lo que había mencionado anteriormente, había señalado esta idea de deconstruir esa forma de ser del sujeto. Entonces, el temblor es el que se experimenta ante ese cruce de llamadas constantes, de llamadas sin fin. Me gusta mucho esto de las llamadas sin fin, y me recuerda lo que plantea Derrida cuando dice que el amor es una demanda infinita, nunca tiene término. El otrx me está reclamando, pidiendo, hablando siempre, y de alguna manera hace patente la condición de exposición ante el otrx que tenemos. 